\title{
Deontological Approach to the Development of Professionally-Communicative Culture Education Managers on Upgrading Courses
}

Tatiana Engersovna Galkina

Natalya Ivanovna Nikitina

Valeria Victorovna Sizikova

Dianida Ivanovna Chemodanova

Veronica Michailovna Grebennikova

Russian State Social University, Russian State Social University, 4, 1, V.Pika, Moscow, 129226, Russia

Doi:10.5901/mjss.2015.v6n4s1p290

\section{Abstract}

Nowadays in the Russian society there made high demands on the level of professional-ethic communicative culture of education managers. Meanwhile the subject concerning the development of education managers communicative culture within refresher courses on basis of pedagogical deontology is not studied enough. This article analyses the essence, structure and revealing levels deontological communicative culture of education managers. The article discusses the results of the diagnostics of personal characteristics of managers in education that affect the manifestation of professional ethic communicative culture of heads of educational institutions. The material illuminates the outcome of long-term work of the authors as teachers of refresher courses for education managers.

Keywords: deontological approach, professional-ethic communicative culture, the Manager of education, refresher courses, psychological-pedagogical diagnostics.

\section{Introduction}

Deontological communicative culture is an integral component of professional culture for a specialist working in the system "person - person".

The problem of development of deontological communicative culture of the heads of educational institutions at extension courses is cross-disciplinary. It is a part of psychology, pedagogy, educational management, philosophy, sociology and is a part of more general problem - the problem of improvement of the continuous professional training of teaching and administrative staff of the educational system $[1,2,3,4]$.

Manager of education is an authorized person in the process of interaction with representatives of various age, social, ethnic, professional groups who contributes to formation of humanistic relationship, dialogical style of communication in the systems "administrator - subordinators", "adult - child", "a manager of education - social partners of educational institution", "pedagogues - schoolchildren's family members". In such case a point of development of manager of education communicative culture within refresher courses is worth being raised on the basis of pedagogical deontological requirements $[5,6,7,8]$.

As a central figure of holistic pedagogical process managers should be able to solve various administrative issues, to manage an educational institution with its well-established traditions and lifestyle as well as to move a school up into a new qualitative level. Arrangement of this point calls for special knowledge in the field of management of education, competence in pedagogical deontology, certain personal and professional characteristics, high communicative standards and professional-ethical skills.

Ability to constant upgrading of personal qualification is considered an important professional quality of education managers $[9,10,11]$. Therefore in up-to-date Russia refresher courses on the issues of pedagogical deontology and educational management are widespread. 


\section{Method}

The material of the present article summarizes the findings of long-term experimental work of the authors (2003-2014) within refresher courses for education managers in Russian State Social University (Russia, Moscow) and its branches in Anapa, Voronezh, Kursk.

2326 trainees of refresher courses for education managers and their deputies have got involved in the work in different stages of the experiment. The subject matter of the courses was the following: "Culture of professional communications of education managers" (144 hours), "Deontology of professional activity of the head of comprehensive institution" (272 hours). 1837 participants of the experimental work is the students professional retraining program "Manager of education" (502 hours). Age practitioners enrolled on courses from 23 to 58 years.

During our work we used the following methods of research

- empirical methods (observation, poll, interviewing, discussion, testing, method of expert judgement; method of self-rating; methods of expression estimation of course trainees' personal characteristics ( $R$. Kettle's $16^{\text {th }}$ factor personality questionnaire; questionnaire $\mathrm{CPI}$ ); K. Thomas's methods; methods of person's orientation diagnostics in communication (B. Bass's "Orientated poll"); I. M. Yusupov's test on empathy expression; examination methods of education managers' motivation-value sphere (Rokitch's value orientations test);

- mathematical methods for data handling (Spearman's rank coefficient of correlation, Pierson's correlation coefficient, Fisher's criterion, Student's T-criterion, Mann-Whitney's criterion, Willcoxon's criterion); as well as package of software application statistical programmes;

- interpretational methods for comprehension of the findings of the long-term experiment (particularly a structural method, i.e. establishment of connection between personality qualities, school head's character traits and level of his communicative deontological culture; data analysis (specifically review of probation journals of refresher course trainees which cite introspection of development stage of deontological communicative culture).

\section{Results}

\subsection{The data on the initial stage of the experiment}

At the initial stage of experimental work diagnostics of level of development of professional students competences, level of knowledge, abilities and skills in the field of personal and business communications and pedagogical deontology required to perform different types of specialist functions was held by the authors.

For diagnostic purposes different tools were used, which included: a survey, poll, method of self-assessment, monitoring, methods of mathematical statistics. The obtained data showed that every third respondent (the total number of respondents was 1835 people) have experienced some difficulties in the implementation of certain types of personal and business communication technologies with so-called difficult communication partners. More than half of respondents said that they aware subjective and objective necessity in the field of mastering the methods of prevention of professional deformation of the personality of education manager that will allow to improve the quality of professional, personal and business communication.

During the experiment the following groups of motives among training course students were revealed and taken into account by teachers of qualification improvement system:

- motives of self-knowledge generic professional features (in the questionnaires the participants pointed out the answers: "I want to understand what prevents me to become a really professional manager", "I wonder whether I can succeed in the profession of the education manager or not", "Need to discover any communication skills, talents" and others);

- motives of socio-professional perception (in the questionnaires students of the courses indicated answers: "I want to know what makes me better than the others in the group", "It is interesting to know how my colleagues treat me", "I should understand whether I can work without conflict with the administration, colleagues" and others);

- motives of professional and personal self-correction (in the questionnaires listeners pointed out the answers: "I want to change myself, to skillfully hide my shortcomings", "Have to learn to influence colleagues", "I want to learn how to control my emotions in the process of professional communication" and others).

The authors of the article have analyzed 1,968 questionnaires of specialists of regional, municipal education authorities, 1,975 questionnaires of parents' community (school board members). The analysis data enabled to elicit the 
following groups of demands which are made by respondents towards demonstration of professional-ethic communicative culture of education managers:

- demands towards maturity of professionally significant merits and capabilities of education managers bearing efficiency of personality-businesslike communication (readiness and capability towards dialogue, competence in adequate estimation of the point of personality and businesslike problems of various participants of holistic pedagogical process; readiness and capability of bearing responsibility for their words, actions; availability towards compromises; skills to collaborate and carry out technologies of management activity with a glance of professional-ethic specifications);

- demands towards maturity of personality features of specialists (self-control, tactfulness, obligation, responsibility, professional tolerance, readiness and capability to hear out, comprehend different opinion);

- demands towards maturity of capability to prevent and settle conflicts, competence towards perception of new concepts, skills of team formation for performance of a certain project.

On the whole manifestations of manager of education communicative culture in actual pedagogical practice are based on interrelationship of such kinds of person culture: communication culture, appearance culture (as a basic component of specialist's positive image), spiritual-moral and deontological culture.

In modern Russian and foreign scientific literature there

\subsection{The role of pedagogical deontology in the development of communicative culture manager education}

is a variety of interpretation of the notion "pedagogical deontology". At the same time the conducted analysis of various scientific-literary sources $[12,13,14,15,16,17,18,19]$ has promoted distinguishing invariant components of this notion. Mostly they interpret pedagogical deontology as:

a) study about professional conduct of a pedagogue which devises regulations and standards of educator's conduct in the field of his labour activity;

b) study about the process of pedagogue's assimilation of normative professional requirements which enable him to apprehend pedagogical reality adequately, to orientate in it, to draw up professionally reasonable strategies and tactics, tasks and plans of professional activity, to regulate his conduct consciously within established professional-normative imperatives;

c) professional ethics which guarantees relationship between participants of pedagogical activity and communication based on confidence as well as includes normative demands towards pedagogue's personality.

In the article authors' opinion pedagogical deontology as an applied scientific subject explores complex of the following concepts:

a) professional-ethic and normative-imperative aspects of relationship between pedagogue and other subjects of integral pedagogical process (in particular professional-ethic standards of relations in the systems "pedagogue - trainee (minor pupil, student, adult trainee)"; "pedagogue - group of trainees"; "pedagogue - pupil (preschooler, schoolchild, student); imperative-codex restrictions (prohibitions) on certain forms and types of interrelations between pedagogue and other subjects of holistic pedagogical process);

b) professional-ethic standards of relationship between pedagogue and other educationalists as well as interrelations between concrete pedagogue and teaching staff; imperative-codex restrictions (prohibitions) on definite forms and types of pedagogue's interaction with colleagues;

c) normative-imperative and professional-ethic aspects of relationship between pedagogue and trainee's microsocial environment (his relatives, friends, neighbours, colleagues in case of an adult trainee etc.);

d) specificity of normative-imperative interrelations between pedagogue and social partners of educational institution, society, state);

e) pedagogue's attitude towards himself as an expert, self-rating the results of his activity, achievements and failures.

Therefore pedagogical deontology contains the system of professionally stipulated normative-ethical (imperativecodex) regulations, restrictions (prohibitions) on interference into another man' inner world (particularly on pedagogical profession representatives' part) and provides the opportunity to impose certain sanctions for their breach.

Pedagogical deontology is directed to explain essence, meaning of ethical-moral dilemmas in the field of pedagogical communications. The goals of pedagogical deontology include elaboration of approaches and mechanisms of prevention of pedagogues' formal attitude towards their functional, determination of upgrading ways of prestige of pedagogical profession in today's society. Besides, pedagogical deontology promotes activization of pedagogue's self- 
development of moral personal features necessary for performance of pedagogical mission of specialist's ethical-moral personal features and prevents their alteration as a result of long-term discharge of professional functions.

\subsection{Meaning and structure of deontological communicative culture of education managers}

On the basis of performed analysis of different approaches towards interpretation of notion "communicative culture of person" $[20,21,22,23]$, as well as in terms of generalization of private scientific research of the article authors there was formulated the following definition: deontological communicative culture of of a manager of education stands for personality integrative-functional formation which reflects complex of variable models of situational normative-role conduct assimilated by a specialist. This kind of culture determines effectiveness and efficiency of professional communications, provides appropriateness of administrative decisions with sociocultural specificity, traditions of educational background taken into account on the basis of professional-ethical norms.

Composition of education managers deontological communicative culture is represented by correlated substructures:

- motivational-value substructure (includes specialist's awareness of significance of professional humanistic ideals and values in the sphere of personality-formal communications and interethnic, polycultural interaction; realization of responsibility for personal professional conduct);

- perceptive substructure (includes ability to listen and demonstrate comprehension of meaning of recipient's statements; capacity to apprehend and realize adequately motivation of people's actions, to estimate emotional condition of communication partner; to take into account sexual-age distinctions of communicative personal features, ethnocultural, individual-personality social-status, professional, confessional, gender and other characteristics of communication partner);

- interactive-practical substructure (performance of professional-applied communicative capabilities and skills in the sphere of personal-formal communications in realities of pedagogical practice; availability and capacity of educationist to adapt to dynamically changing terms of labour activity; knacks to control one's emotional condition, competence to self-regulate behavioral and speech reactions in difficult situations of personal-formal communications);

- professional-acmeological substructure (adequate specialist's self-esteem of strong and weak features of his individual communicative deontological culture, specifics of his professional conduct, acknowledgement of necessity of work at his defects and their removal, urge towards realization of programmes of personalityprofessional self-development).

\subsection{Professional-educational technologies of refresher course for development deontological communicative culture of education managers}

Most of all principles of person-oriented training of course trainees are corresponded with technology of pedagogical workshops which gives every participant an opportunity to fulfill oneself in studies with trainee's subject (professionalpersonal) experience, capabilities, interests as a support [24].

It is high time to consider the main stages of workshop activity.

On the phase "Problem statement" participants get involved into problem situation of workshop performance (for example, "Prevention and solution of ethnic conflicts in educational institutions" or "Prevention of conflicts in school staff"), it arouses their personal attitude towards point of discussion, relevant emotional spirit and interest.

On the stage "Self-examination" teacher (workshop guide) supposes individual task for every trainee's testing of his own actual possibilities within assigned problem as an objective (for example, to give an example from personal practice when analogical conflict has been settled or prevented successfully).

On the phase "Cooperation" work in microgroups is arranged (the groups can be homogeneous either heterogeneous, for example, according to the factual job positions of refresher course trainees), elaboration of group position on exploring problem.

On the stage "Defense (presentation)" each microgroup states and defenses its position (opinion) towards ways of problem solution, discussion can occur as well as creative designing of results of group activity.

On the phase "Reflection" individual (or microgroup) analysis of positive and negative aspects of workshop performance and resume of solution of problem situation takes place.

In the opinion of pedagogical workshop participants they transfer technologies of group work in course period to educational process of their educational institution more willingly. 
Professional culture and personal features of refresher course teachers play a special role in the process of development of deontological communicative culture.

\subsection{Levels of formation deontological communicative culture of education managers}

The authors of the article have been exploring specificity of manifestations of concrete deontological communicative culture of education managers in real terms of their work practice for 10 years. As a result of data analysis there were distinguished the following typical levels of this culture manifestation of education managers.

Situational-adoptive level of manifestation deontological communicative culture is characterized: by adequate professional-speech reactions in typical situations of labour activity; by situational oriented speech, formation of basic reflexive-perceptive abilities as well as elementary basic capacities of self-regulation of emotional condition.

Administrative-discrete level of manifestations of communicative deontological culture of education managers is represented by: acknowledgement of professional value of norms of pedagogical deontology; by presence of knowledge about structure and characteristics of personal communicative style; by reflexivity of single aspects of professional communications; ormation of communicative skills to achieve positive result while performing the main functions of professional activity; by episodical (discrete) indication of quite a high level of empathic experience; comprehension and acceptance of single individual features of another man; outcome of formation of basic abilities of self-regulation of professional-speech activity, emotional condition, behavioral reactions.

Systemic-administrative level is characterized by: advanced motive towards systematic self-perfection of communicative culture on the basis of requirements of pedagogical deontology aimed at achievement of maximal selfrealization in professional sphere of educational management; availability of systemic knowledge about characteristics of one's communicative style; outcome of formation of wide range of devices of observance of professional-ethic standards in practical activity, congruence of verbal and nonverbal speech in context of concrete professional situation; reflexivity in sphere of professional communications.

Professional-creative level is represented by: constant effort towards acquirement of various psychotechnics of self-improvement of education manager's style of communicative culture; developed capabilities of self-control in sphere of personal-formal communications; high level of professional-social adaptation in constantly regenerative terms of labour activity; flexibility, variability, tactfulness of professional-speech conduct of specialist even in nonstandard situations; harmonic maturity of all structural components of communicative culture; availability of system of individual techniques of self-regulation of emotional condition, behavioral reactions; capability of improvisation; achievement of high results of professional activity; "acquisition of state of inner comfort", attainment of sense of satisfaction due to outcome of pedagogical work, most of which are stipulated by usable individual-style ways of manifestation of high level of education manager's deontological communicative culture.

\subsection{Correlation between deontological communicative culture of school head and his professional competence}

Taking into consideration the fact that specialist's culture is interpreted as weight average indicator which correlates with definite level of his professional competence and reflects organization degree of necessary competences [25, 26], the authors of the article have elicited competences which form substantial basis of school head's deontological communicative culture.

In the present article the authors consider competence as one of basic characteristics of subject of professional activity which is causally connected with criteria of effective (successful, productive) action in concrete professional situation (by solution of certain professional task).

On purpose of exposure of totality of competences which form sufficient basis of deontological communicative culture of school head the authors of the article have analyzed qualifying requirements and professiograms of education manages as well as specification of implementation of deontological communicative standards of interaction between heads of educational institutions and different categories of participants (subjects) of integral pedagogical process in natural labour terms of these specialists.

On the basis of analysis of the findings the authors of the article have elicited the following deontological communicative competences of school heads:

- assertive competence (includes capabilities to prevent conflicts and negotiate to attain compromise; skills of professional perception in personal-formal communication; will and capacity to work in team);

- normative-imperative competence (includes ability to determine cultural-value zones of contradictions and possible conflicts in professional practice, particularly in the sphere of interethnic communication, capacity 
towards their constructive settlement; observance of confidence);

- ethnocultural competence (includes capabilities to apprehend and accept specific characteristics of another cultures; capacities and skills to perform personality-formal communications with ethnocultural traditions and standards taken into account);

- social-status competence (includes capacities to arrange professional communication with representatives of different social groups by means of ethic-axiological approach towards analysis of essence and subjectmatter, forms and methods of formal and private communication);

- ethnoconfessional competence (includes comprehension of characteristics of religious views of representatives of different nationalities, specificity of conduct stipulated by religious standards; capacity towards interaction with representatives of various confessions and religions; capability to arrange privateformal intercourse taking into consideration religious and confessional features of partners on contact);

- interactive competence (includes adequate comprehension, understanding of information in the course of performance of professional activity; availability and legibility of one's own professional-informational message, capacity to interact with partners on communication within context and specificity of concrete situation).

An experts' group of seven members evaluated the refresher course "Education manager" (502 hours) graduates' level of system arrangement of the above-listed competences. To perform evaluation the authors of the article have elaborated special diagnostic record charts which enabled to estimate the level of performance of competences during classes (seminar, practicum, management game), various kinds of trainings, probations, defence of course and graduation projects, in different forms of scientific-research activity.

In Table 1 there pointed out average rating (10 score scale) on all competences, mean-square (standard) deviation of rates and data concerning probabilities of equality of average values. There was used function TEST of application MS Excel evaluating probability for observed value of $t$-criterion. The accounts determine significance of distinctions (with significance level of 0,05 ) of average values for five competences.

Table 1. Results of expert rating of formation of deontological communicative competences of graduates of professional retraining courses "Education manager" [27]

\begin{tabular}{|l|c|c|c|c|c|}
\hline \multirow{2}{*}{ Competences } & \multicolumn{2}{|c|}{ Graduation of 2011 } & \multicolumn{2}{|c|}{ Graduation of 2014 } & \multirow{2}{*}{$\mathbf{p}$} \\
\cline { 2 - 6 } & $\bar{x}_{1}$ & 1 & $\bar{x}_{2}$ & 2 & \\
\hline Interactive competence & 8.02 & 1.64 & 8,78 & 1,12 & $<0,05$ \\
\hline Normative-imperative competence & 8.76 & 1.13 & 9.01 & 0.96 & $<0,05$ \\
\hline Assertive competence & 8.11 & 1.52 & 8.64 & 1.09 & $<0,05$ \\
\hline Ethnocultural competence & 7.89 & 1.45 & 8.12 & 0.97 & $<0,05$ \\
\hline Social-status competence & 8.13 & 1.76 & 8.46 & 1.68 & $<0,05$ \\
\hline Ethnoconfessional competence & 7.62 & 2.05 & 7.96 & 1.83 & $>0,05$ \\
\hline
\end{tabular}

\section{Discussion}

In the research process and its results, the authors have identified the following diagnostic levels of individual features of refresher training students (education managers).

The first level of diagnostics is the level of detection of natural preconditions of communicative and deontological culture of a manager of education manifestations. Temperament, style professional thinking of a specialist (including flexibility and rigidity, creativity and fertility thinking); the strength or weakness of nervous system, which, in particular, is reflected in the self-regulation mechanisms of excitation, aggressiveness, braking and other were diagnosed by special techniques at this level.

The second level of diagnostics is the detection level of severity of individual peculiarities of communicative activity of training participants. This level of diagnostics allows taking into account the impact of social conditions of development of personality of a head of school, in particular, the influence of education and self-education on the symptoms of the communicative culture of a person. Personal orientation in communication (for itself and on cooperation (partnership), on the job (result); peculiarities of accentuations of character, which affect the manifestation of communicative culture of a specialist; the system of values of the person and other were diagnosed on this level.

The third level of diagnostics is the detection level of severity of professionally important qualities of a specialist, 
which are significant for the development of deontological communicative culture of a school leader and was formed by students in periods of workshops and training, and during the periods of self-employment. In particular, special valid test methods diagnosed level of professional reflection of a teacher, the tactics of behavior in conflict situations, etc.

Evaluation of effectiveness of development process deontological communicative culture of education managers within advance training course

Valid diagnostic techniques to determine the dynamics of changes in personal and professionally important characteristics of students, which are important for the development of the system of training the deontological culture of communication managers of education were selected. Thus, in particular, the comparison of data source and final examination of the students of professional retraining under the program "Manager of education" (502 hours) showed positive dynamics in the following professional and personal qualities of specialists:

a) according to the results of the test to identify empathic abilities by I.M. Yusupov the number of students with a high level of empathy has increased from 39.7\% (among 2011 graduates) to 51.2\% (among 2013 graduates);

b) according to "Indicative questionnaire" by V. Bass the percentage of students with a focus on the interaction increased from $45.3 \%$ to $62.8 \%$ (2011 and 2013 respectively);

c) according to the results of the test by V.V. Boyko the majority of graduates developed a high professional level of tolerance $-41.3 \%$ (among 2011 graduates) to $56.8 \%$ (among 2013 graduates);

d) according to the results of the questionnaire by V.I. Morosanova the number of students with a high level of development of ability for self-regulation of emotional state and behavior significantly increased from $43.5 \%$ to $64.2 \%$;

e) according to the results of the questionnaire by A.K. Osnitskii the number of adult students with a high level of development of reflective processes increased from $41.6 \%$ to $55.2 \%$.

On the final stage of the experiment there were fixed significant alterations $(p<0,05)$ in frequency of behavioral strategy manifestations in conflict situations (due to K. Thomas's methods). Therefore, in the graduation of education managers of the year 2014 there increased the number of respondents (in comparison with the graduation of the year 2011) who choose the strategy "interaction" (48 per cent - the graduation of 2014; 26 per cent - the graduation of 2011); the strategy "compromise": 46 per cent in 2014; 31 per cent in 2011. In addition to that there was set decrease of frequency of choice of the strategy "contest" for the graduation of education managers of the year 2014 (13 per cent 2014, 25 per cent - 2011).

The questionnaire by R. Cattell helped to determine dynamics of development of professionally important personal characteristics of students of professional retraining program "Management in education", influencing deontological and professional communicative culture of a head of an educational institution (table 2).

Table 2. Indicators of important professional and personal characteristics of students at program of professional retraining "Education manager" influencing deontological and communicative culture of a school leader [27]

\begin{tabular}{|l|c|c|c|c|c|}
\hline \multirow{2}{*}{ Index (in points) } & $\mathbf{2 0 1 1}$ graduates & $\mathbf{2 0 1 4}$ graduates & $\mathbf{R}$ \\
\cline { 3 - 6 } & $\bar{x}_{1}$ & 1 & $\bar{x}_{2}$ & 2 & \\
\hline $\begin{array}{l}\text { Factor G - moral normativity: responsibility, respect for legal and social norms, } \\
\text { demanding of themselves and others in terms of observance of norms and rules }\end{array}$ & 7.41 & 1.83 & 7.94 & 1.41 & $<0,05$ \\
\hline $\begin{array}{l}\text { Factor Q3 - discipline: the persistence in achieving goals overcoming obstacles on the } \\
\text { way to it for the expense of willpower self-control of emotions and behavior; the ability } \\
\text { to plan their time and procedure }\end{array}$ & 6.26 & 1.72 & 6.95 & 1.34 & $<0,05$ \\
\hline $\begin{array}{l}\text { Factor Q1 - flexible thinking: the receptivity to new, rapid situation analysis, } \\
\text { understanding the essence of the problem, heuristic thinking, prone to } \\
\text { experimentation, search of new non-standard ways of solving the problem, } \\
\text { independence in solving of problems, reflection of failure in the experiment }\end{array}$ & 5.37 & 1.52 & 5.93 & 1.73 & $<0,05$ \\
\hline $\begin{array}{l}\text { Factor M - adaptability: successful adaptation in hardcoded rules and situational } \\
\text { conditions, a practical mind, realism in actions, the integrity of the task }\end{array}$ & 7.81 & 1.49 & 8.13 & 1.53 & $<0,05$ \\
\hline $\begin{array}{l}\text { Factor N - flexibility: quick calculation of possible solutions of a problem and the } \\
\text { optimal choice, insightful towards others, attention to the nuances and details of a } \\
\text { situation }\end{array}$ & 5.19 & 1.62 & 5.88 & 1.16 & $<0,05$ \\
\hline
\end{tabular}

As a result of the research by means of questionnaire "Self-actualizing test (SAT)" personality of each refresher course trainee (participant of experiment) has been described by psychologically informative factors. Thus, for example, the rates according to the scale "Sociability (C)" is characterized by human ability of quick establishment of deep emotionally 
saturated contacts with people, subject-subjective intercourse; the rates according to the scale "Flexibility of conduct (Ex)" diagnose the degree of subject's flexibility in realization of his personal and professional values in conduct during interaction with surrounding people, ability to react on the changing situation quickly and adequately; the scale "Synergy (Sy)" determines human capability of holistic perception of world and people, of comprehension of coherence of oppositions. The scales "Sociability" and "Acceptance of aggression" make up the block "Interpersonal sensitiveness" which characterizes the level of empathy, social perception. Thus, in 2014 the graduates of the programme "Education manager" ( $n=128)$ the rates according to the scale "Sociability $(C)$ " increased to 18.61 (in comparison with 10.26 graduates of the same programme of 2011); due to the block "Interpersonal sensitiveness" - from 8.3 to 17.9; according to the scale "Flexibility of conduct (Ex)" - from 7.3 to 16.2; according to the scale "Synergy (Sy)" - from 3.1 to 10.5 .

\section{Conclusion}

The basis of deontological communicative culture is the ability to understand other's and create own programmes of communicative behavior, which is appropriate in particular situations of personal-practical communication, and also the complex of abilities to choose linguistic forms and ways of self-expression for particular communicative actions accordingly, the abilities to operate with information easily, reasonably, intentionally in the frames of professionally and personally important themes of personal and business contact.

The results of diagnostics showed the need for systematic work with students of refresher training with the purpose of reception of positive dynamics of development of dialogue orientation of an individual specialist on interaction as one of the constituents of professional essence of the education manager.

On the whole it can be stated that the system of advance qualification of education managers is able to provide effectiveness of development of their deontological communicative culture on condition that:

- studying process of course training is based upon objective evaluation of specificity of adult trainees' contingent (specialists-practitioners) and logics of their professional-personal development in the system of advance training;

- in content-methodic basis of course training specific characteristics of managerial labour of school administrators, tendencies of development of educational systems in regions and Russia as a whole, actual and perspective demands of labour market for education managers are considered fundamental.

In summary, we can state that deontologically oriented educational process of an institution in the system of refresher training for pedagogical staff with all its diverse realities becomes the new context of professional personal development of person, giving him plenty of opportunities for self-improvement in the sphere of professional communications.

\section{References}

L. M. Mitina, Psychology of professional development of teachers. Moscow: Publishing House "Flinta" of the Moscow Socialpsychological Institute, 1998, 26-38.

D. Carr, Professional and personal values and virtues in education and teaching. Oxford Review of Education, 32(2006), 171-183.

B. Davies, Rethinking schools and school leadership for the twenty-first century: changes and challenges. The International Journal of Educational Management, 16(4) (2002), 196-206.

P. Hallinger, Leadership for learning: Lessons from 40 years of empirical research. Journal of Educational Administration, 49(2011), 125142.

V. M. Grebennikova, Deontological approach towards development of professional-communicative culture of administrators of comprehensive schools in the system of advance qualification (Doctoral dissertation). Russian State Social University, Moscow, 2012, 8-35.

T. Bergem, Examining aspects of professional morality. Journal of Moral Education, 22(3) (1993), 297-312.

D. Carr, Character and moral choice in the cultivation of virtue. Philosophy, 78(2) (2003), 219-232.

R. Cummings, S. Harlow \& C. D. Maddux, Moral reasoning of in-service and pre-service teachers: a review of the research. Journal of Moral Education, 36 (1) (2007), 67-78.

K. Leithwood, A. Harris \& D. Hopkins, Seven strong claims about school leadership. School Leadership \& Management, 28(2008), 2742.

T. W. Miller \& J. M.Miller, Educational leadership in the new millennium: a vision for 2020. International Journal of Leadership in Education, 4(2001), 181-189.

N. I. Nikitina \& S.N. Tolstikova, Professional-communicative culture of specialists in the sphere of international cooperation. Human capital, 2 (38) (2012), 160-163.

B. M. Bim-Bad, Anthropological ground of theory and practice of modern education. Moscow: Publishing house of University of Russian 
Academy of Education, 1994, 28-35.

E. Campbell, The ethics of teaching as a moral profession. Curriculum Inquiry 38(4) (2008), 357-385.

M. Freakley, Ethics education with pre-service teachers. The Australasian Journal of Philosophy for Children, 15(2) (2007), 3-13.

G. M. Kodzhaspirova, Pedagogical anthropology. Moscow: Gardariki, 2005, 13-18.

K. M. Levitan, Fundamentals of pedagogical deontology. Moscow: International Humanitarian Foundation "Knowledge", 1994, 21-26.

T. Lovat, Ethics and ethics education: professional and curricular best practice Curriculum perspectives, 18(1) (1998), 1-8.

L. E. Beyer, The moral contours of teacher education. Journal of Teacher Education, 48(4) (1997), 245-254.

G. Colnerud, Teacher ethics as a research problem: Syntheses achieved and new issues. Teachers and Teaching: Theory and Practice, 12(3) (2006), 365-385.

L. P. Bueva, Man, culture and education in crisis socium. Alma mater, 4(1997), 11-17.

A. Leontyev, Psychology of communication. Moscow: Publishing house "Sense", 1997, 33-38.

K. Markova, Psychology of professionalism. Moscow: International Humanitarian Foundation "Knowledge", 1998, 46-52.

I. A. Zimnyaya, Culture. Being educated. Professionalism of specialist. Moscow: Research Centre of problems of quality of specialists' training, 1998, 5-13.

N. I. Nikitina \& V. M.Grebennikova, Interactive technologies of education in the system of advance qualification of administrators of comprehensive schools. Bulletin of University (State University of Management), 13(2012), 68-71.

E. F. Zeer, Modernization of vocational education: competence approach. Moscow: Moscow Social-psychological Institute, 2005, 21-28.

L. V. Mardakhaev, Professional culture of social pedagogue. Social pedagogy edited by Nikitin V. A. Moscow: Moscow SocialPsychological Institute (2002), 234-236.

O.V.Kaurova, E.M.Kryukova, A.N.Maloletko, A.V.Deryabina, O.S. Yumanova, Modern trends in development of tourism statistics in the world and in Russia. Life Science Journal, 11(4) (2014); 451-454. 